OPEN ACCESS

Edited by:

Menghong $\mathrm{Hu}$,

Shanghai Ocean University, China

Reviewed by:

Ming Zhang,

China Jiliang University, China

Ding Tengda,

Shenzhen University, China

Huang Wei,

Ministry of Natural Resources, China

*Correspondence:

Hangjun Zhang

13819172516@163.com

Specialty section:

This article was submitted to

Aquatic Physiology,

a section of the journal

Frontiers in Physiology

Received: 08 February 2020 Accepted: 20 March 2020

Published: 15 April 2020

Citation:

Zhong $Y$, Shen L, YeX, Zhou D, He Y, Li Y, Ding Y, Zhu W, Ding J and

Zhang $H$ (2020) Neurotoxic

Anatoxin-a Can Also Exert

Immunotoxicity by the Induction

of Apoptosis on Carassius auratus

Lymphocytes in vitro When Exposed

to Environmentally Relevant

Concentrations.

Front. Physiol. 11:316.

doi: 10.3389/fphys.2020.00316

\section{Neurotoxic Anatoxin-a Can Also Exert Immunotoxicity by the Induction of Apoptosis on Carassius auratus Lymphocytes in vitro When Exposed to Environmentally Relevant Concentrations}

Yuchi Zhong ${ }^{1}$, Lilai Shen ${ }^{1}$, Xueping Ye', Dongren Zhou' ${ }^{2}$ Yunyi He' ${ }^{1}$, Yan Li', Ying Ding ${ }^{1}$, Weiqin Zhu ${ }^{1}$, Jiafeng Ding ${ }^{1}$ and Hangjun Zhang ${ }^{1 *}$



'School of Life and Environmental Sciences, Hangzhou Normal University, Hangzhou, China, ${ }^{2}$ Zhejiang Institute of Freshwater Fisheries, Huzhou, China

Hazardous anatoxin-a (ANTX-a) is produced by freshwater algal blooms worldwide, which greatly increases the risk of consumer exposure. Although ANTX-a shows widespread neurotoxicity in aquatic animals, little is known about its mechanism of action and biotransformation in biological systems, especially in immunobiological models. In this study, transmission electron microscopy results showed that ANTXa can destroy lymphocytes of Carassius auratus in vitro by inducing cytoplasmic concentration, vacuolation, and swollen mitochondria. DNA fragmentations clearly showed a ladder pattern in agarose gel electrophoresis, which demonstrated that the apoptosis of fish lymphocytes was caused by exposure to ANTX-a. Flow cytometry results showed that the apoptotic percentage of fish lymphocytes exposed to 0.01 , $0.1,1$, and $10 \mathrm{mg} / \mathrm{L}$ of ANTX-a for $12 \mathrm{~h}$ reached 18.89, 22.89, 39.23, and 35.58\%, respectively. ANTX-a exposure induced a significant increase in reactive oxygen species (ROS) and malonaldehyde (MDA) in lymphocytes. The activities of superoxide dismutase $(\mathrm{SOD})$, catalase (CAT), glutathione reductase (GR), glutathione peroxidase (GPx), and the glutathione (GSH) content of the $0.01 \mathrm{mg} / \mathrm{L}$ ANTX-a-treated group decreased significantly by about $41,46,67$, and $54 \%$ compared with that of the control group ( $p<0.01$ ), respectively. Although these observations were dose-dependent, these results suggested that ANTX-a can induce lymphocyte apoptosis via intracellular oxidative stress and destroy the antioxidant system after a short exposure time of only $12 \mathrm{~h}$. Besides neurotoxicity, ANTX-a may also be toxic to the immune system of fish, even when the fish are exposed to environmentally relevant concentrations, which clearly demonstrated that the potential health risks induced by ANTX-a in aquatic organisms requires attention.

Keywords: apoptosis, ANTX-a, oxidative stress, antioxidant enzymes, fish lymphocytes 


\section{INTRODUCTION}

Cyanotoxins are toxic secondary metabolites produced by algal blooms, which are widely distributed in fresh water in various countries and regions of the world (Du et al., 2019; Ruibal-Conti et al., 2019). Several studies have shown that cyanotoxins, such as anatoxin-a (ANTX-a), and microcystins can bioaccumulate in aquatic biota, which poses a huge threat to the biological health and ecological environment, especially that of aquatic organisms (Ibelings and Havens, 2008). Svircev et al. (2019) investigated that there were 183 cases of cyanotoxin poisoning in humans and animals as of 2019. ANTX-a, chemically identified as 2-acetyl-9-azabicycle[4.2.1]non-2-ene (Smith and Lewis, 1987), is a neurotoxin that can be isolated from different genera of cyanobacteria, such as Oscillatoria, Anabaena flos-aquae, Aphainizomenon, Cylindrospermum, etc. (Cires and Ballot, 2016). Although microcystins seem to be more common than ANTX-a, the latter cause more organism poisonings in Europe, Australia, and North America than those caused by microcystins (Fitzgeorge et al., 1994). Dog and cattle poisonings related to ANTX-a were reported in six places in Canada between 1961 and 1975 (Trainer and Hardy, 2015). ANTXa is becoming increasingly recognized as a potential risk to both animal and human health, which has been incorporated into laws and regulations regarding the water security of several countries (Rodriguez et al., 2017). In 2015, the U.S. government passed an amendment to the "Drinking Water Protection Act" (PL 114-45) that requires the implementation of the best available technology to assess the risks to human health of public water polluted by cyanotoxins such as ANTX-a (Metcalf et al., 2018).

ANTX-a is abundant in the environment and leads to detrimental effects on various organisms through drinking water and food. For instance, Carneiro et al. (2015) revealed that ANTX-a can damage proteins playing toles in carbohydrate metabolism, cell structure maintenance, stress response, etc., of male and female zebrafish. As hazardous neurocyanotoxins, ANTXs are strong agonists of the neural nicotinic cholinergic receptor existing in the postsynaptic membrane (Loftin et al., 2016). Animals reportedly die from exposure to ANTX-a following toxic response to acetylcholine receptor inhibition at neuromuscular junction (Carneiro et al., 2015). Chia et al. (2019) revealed that high-dose injection or ingestion of ANTXa can cause fatal suffocation in mammals and induces oxidative stress. The influence of ANTX-a on the biological nervous system has been extensively investigated because ANTX-a is toxic to this system; nervous system diseases are characterized by disordered muscle bundles, decreased motor ability, tremor and gait changes, irregular breathing (Rymuszka and Sieroslawska, 2009). However, studies on the toxic effects of ANTX-a have focused on its neurotoxicity, but studies on ANTX-ainduced immunotoxicity have rarely been conducted. Moreover, little was known about its effects on the immune system of fish. Similar to other cyanotoxins, ANTX-a is extensively distributed in natural waters worldwide; this phenomenon has prompted researchers to investigate ANTX-a in natural waters. Ruiz et al. (2013) found ANTX-a for the first time in fresh water in South America. Heldman et al. (2008) reported the concentration of ANTX-a was $13 \mu \mathrm{g} / \mathrm{L}$ in a German lake, while the total concentration of ANTX-a in water reached $1750 \mu \mathrm{g} / \mathrm{L}$ in the United States (Bumke-Vogt et al., 1999). Considering that water quality is essential for fishes, researchers should investigate the immunotoxic effects of ANTXa on fish.

Previous studies have shown that cyanotoxins, including nodularin and microcystins, can induce antioxidant system perturbation of Carassius auratus, resulting in oxidative stress (Sieroslawska and Rymuszka, 2019). Immune system perturbation caused by cyanotoxins can be indicated by the activity of antioxidant enzymes and levels of lipid peroxidation and reactive oxygen species (ROS) in immune cells (Huguet et al., 2019). As is well-known, overproduction of ROS or the decrease of cellular antioxidant levels can lead to the imbalance of cellular oxidation, which is called oxidative stress. Formation of ROS may lead to attack and destruction of important cell components, such as DNA and proteins, which may lead to permeability damage, membrane fluidity damage (FernandezBlanco et al., 2015). Production of ROS can also be stimulated by exposure to ANTX-a, thereby resulting in oxidative stress. Teneva et al. (2005) revealed that ANTX-a can induce the generation of ROS in cultured rat thymocytes. Antioxidant system perturbation is closely related to the occurrence of oxidative stress. As the main antioxidant enzymes in the first line of defense of the antioxidant system, catalase (CAT), superoxide dismutase (SOD), etc., can effectively scavenge excess oxygen free radicals in immune cells. Our previous study found that nodularin induced the apoptosis of C. auratus lymphocytes by oxidative stress and the mitochondrial apoptotic pathway (Zhang et al., 2012). In particular, it is necessary to study the response of the immune system of vertebrates to ANTX-a, especially in aquatic organisms.

This study utilized ANTX-a as the target pollutant of lymphocytes isolated from C. auratus for investigating the toxic effects of different exposure concentrations on immune cells in vitro. The results were discussed mainly from the aspect of antioxidant response to illuminate the mechanism of oxidative stress in lymphocytes.

\section{MATERIALS AND METHODS}

\section{Chemicals and the Toxin}

Purified ANTX-a (CAS No. 64285-06-9, $\mathrm{C}_{10} \mathrm{H}_{15} \mathrm{NO}$, MW = 165.23) was purchased from Sigma (St. Louis, MO, United States). Lymphoprep was purchased from Huadong Pharmaceutical (Zhejiang, China). Fetal calf serum (FCS) and RPMI-1640 medium were acquired from Hangzhou Key Shengwu (Hangzhou, China). Malonaldehyde (MDA), SOD, glutathione (GSH), CAT, glutathione-s-transferase (GST), glutathione reductase (GR), and glutathione peroxidase (GPx) assay kits were all purchased from Nanjing Jiancheng Bioengineering, Inc. (Jiangsu, China).

3-(4,5-Dimethylthiazol-2-yl)-2,5-diphenyl tetrazolium bromide, propidium iodide (PI), and rhodamine 123 
assay kits were obtained from Beyotime Institute of Biotechnology (Shanghai, China). Other reagents used were purchased from commercial sources unless otherwise specified.

\section{Experimental Fish}

From the hatchery of Freshwater Fisheries Research Institute (Zhejiang, China), we obtained about 400-500 g of bisexual C. auratus (6-10 months old). All experimental fish were raised and kept in circulating water with indoor temperature controlled at $25 \pm 1{ }^{\circ} \mathrm{C}$. Feed fish with pellet feed at a daily ration of $0.7 \%$ of their body weight. After 2 weeks, healthy fish were utilized for subsequent studies.

\section{Lymphocyte Isolation and Cell Culture}

The method of isolating lymphocytes was based on that of Zhang et al. (2008). C. auratus were sacrificed by decapitation, and their kidneys were removed. The mixed tissues were passed through the nylon screen. The cells were washed twice in serum-free cold medium and layered onto 1.5 volumes of Lymphoprep (density adjusted to $1.077 \mathrm{~g} / \mathrm{mL}$ ). After centrifugation at $640 \times g$ for $30 \mathrm{~min}$, non-adherent lymphocytes were carefully obtained by washing with PBS solution three times. Finally, the cells were cultured in an antibiotic-free RPMI-1640 medium containing 5\% FCS. Use a hemocytometer, the number of cells was counted. The obtained cells were divided into five groups and treated with different concentrations of ANTXa for $12 \mathrm{~h}$.

\section{Electron Microscopy Observation}

The lymphocytes were washed with PBS and immobilized overnight in $2.5 \%$ glutaraldehyde at $4^{\circ} \mathrm{C}$. The cells were washed three times in PBS (0.1 M, pH 7.0) for 15 min each time, and then immobilized at osmium tetroxide (1\%) for $1-2 \mathrm{~h}$. Then, in Epon 812, the treatments were dehydrated and embedded by a gradient alcohol series and acetone. Finally, ultra-thin sections were prepared and stained with lead citrate and uranyl acetate, and then viewed under a transmission electron microscope (Philips, TECNAL-10).

\section{DNA Ladder Assay}

A DNA ladder assay was performed via gel electrophoresis, as previously described. All groups of exposed lymphocytes were acquired and washed twice with cold PBS. Intracellular DNAs were then extracted utilizing an AxyPrep genomic DNA mini kit purchased from Axygen Biotechnology (Hangzhou, China), and electrophoresed using an agarose gel (1\%). Finally, the extracted samples were stained with ethidium bromide (30 $\mu \mathrm{g} / \mathrm{L})$ and visualized utilizing a Kodak Gel Logic 200 (Molecular Imaging, NY, United States) using $1 \mathrm{~kb}$ as a size marker.

\section{Apoptosis Detection by Flow Cytometry}

The cells were treated with different ANTX-a concentrations for $12 \mathrm{~h}$, washed with cold PBS, and fixed in ethanol (70\%) at $4^{\circ} \mathrm{C}$ for 1 day. The detailed detection method mainly refers to the method of Tavakkol-Afshari et al. (2008). The lymphocytes were washed with PBS twice and treated with PI staining buffer $(50 \mu \mathrm{g} / \mathrm{mL})$ and RNase $(0.1 \mu \mathrm{g} / \mathrm{mL})$ at $20^{\circ} \mathrm{C}$ for $30 \mathrm{~min}$. The cells were filtered using a BD Falcon circular tube (No. 352235, Becton Dickinson, Franklin Lakes, NJ, United States) before analysis with a Guava easyCyte 8HT flow cytometer (Merck Millipore, Darmstadt, Germany).

\section{Intracellular ROS Assay}

Lymphocytes were collected and homogenized in cold PBS after incubating with different ANTX-a concentrations for $12 \mathrm{~h}$. The cells were exposed to dichloro-dihydrofluorescein diacetate. The final concentration was set at $10 \mu \mathrm{M}$ and maintained at the room temperature for $20 \mathrm{~min}$. The lymphocytes were passed through a cell mesh and homogenized before detection because they may adhere to the walls of the centrifuge tubes. The lymphocytes were analyzed by flow cytometer (Guava EasyCyte 8HT). The excitation wavelength and emission wavelength were 488 and $525 \mathrm{~nm}$, respectively.

\section{Detection of GSH and MDA Contents}

Lymphocytes were obtained and homogenized by centrifugation at $640 \times g$ for $15 \mathrm{~min}$ at $4^{\circ} \mathrm{C}$ in cold PBS. The GSH and MDA contents were determined according to the manufacturer's instructions for the use of the assay kits (Jiancheng, Nanjing, China).

\section{Measurement of Antioxidant Enzyme Activities}

The activities SOD, CAT, GR, GPx, and GST were detected in this study. SOD activity was detected according to the instructions in the enzyme activity assay kit (WST-1). Lymphocytes were obtained and homogenized by centrifugation at $640 \times g$ for $15 \mathrm{~min}$ at $4^{\circ} \mathrm{C}$ in cold $\mathrm{PBS}$ to obtain the supernatant. The mixture was incubated at $37^{\circ} \mathrm{C}$ for $20 \mathrm{~min}$. Finally, using a multimode microplate reader (Infinite M1000), the absorbance was measured at $450 \mathrm{~nm}$. The sample activity was expressed in unit/mg protein. The activities of other enzymes, namely, CAT, GR, GPx, and GST, were detected according to the instructions indicated in the corresponding assay kits.

\section{Statistical Analysis}

All experimental data were recorded and calculated in Microsoft Excel ${ }^{\circledR}$ software, which were presented as the mean \pm standard deviation (SD) of five independent experiments performed in duplicate and triplicate. The samples were analyzed by oneway ANOVA, and $p<0.05$ and $p<0.01$ were considered statistically significant.

\section{RESULTS}

\section{Ultrastructural Observations of Lymphocytes}

The morphological changes of lymphocytes of $C$. auratus in vitro treated with ANTX-a (0 and $100 \mu \mathrm{g} / \mathrm{L})$ for $12 \mathrm{~h}$ 

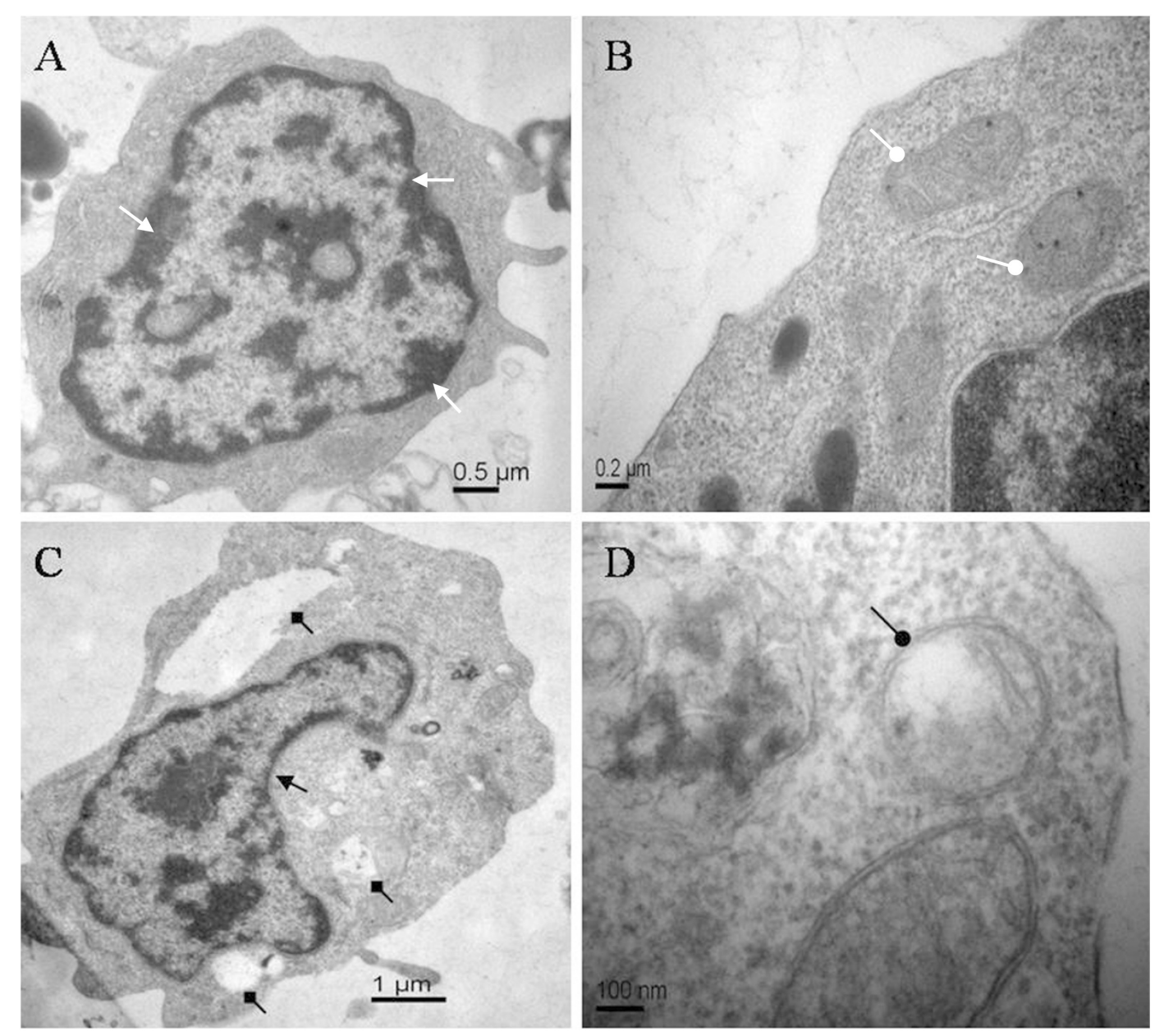

FIGURE 1 | Electron micrographs of carp immunocytes treated with ANTX-a: (A,B) control cells showed homogeneous nuclear chromatin (white triangle arrow) and normal mitochondria (white circular arrow). (C,D) Cells treated with $100 \mu \mathrm{g} / \mathrm{L}$ ANTX-a for $12 \mathrm{~h}$ showed a condensed cytoplasm (black triangle arrow) with hollow bubbles (black square arrow) and slight swelling of the mitochondria (black circular arrow).

were observed through transmission electron microscopy. Figures 1A,B show the normal lymphocytes of the control group, and Figures 1C,D show the lymphocytes exposed to $100 \mu \mathrm{g} / \mathrm{L}$ ANTX-a for $12 \mathrm{~h}$. In the control group, the lymphocytes exhibited homogeneous nuclear chromatin (white triangle arrow, Figure 1A), and the mitochondria were not expanded (white circular arrow, Figure 1B). The morphological changes of lymphocytes exposed to $100 \mu \mathrm{g} / \mathrm{L}$ ANTX-a for $12 \mathrm{~h}$ were observed; condensed cytoplasm (black triangle arrow), slight swelling of the mitochondria (black circular arrow), and vacuolization (black square arrow) were observed in these lymphocytes (Figures 1C,D). These results indicated that ANTXa damaged the lymphocytes of $C$. auratus.

\section{ANTX-a-Induced DNA Fragmentation in Lymphocytes}

Biochemically, the fragmentation of the nuclear chromatin of DNA is a typical character of apoptosis (Bortner et al., 1995), which leads to $180-200$ bp fragments or complete
DNA fragments. DNA fragmentation of ANTX-a-exposed cells was evaluated using agarose gel electrophoresis. The control only showed the total genome strip, and the total DNA extracted from cells exposed to different ANTX-a concentrations for $12 \mathrm{~h}$ distinctly showed a ladder pattern (Figure 2). These results demonstrated that ANTX-a can trigger apoptosis in the lymphocytes of C. auratus in vitro.

\section{Flow Cytometric Determination of ANTX-a-Induced Apoptosis}

The percentages of apoptotic cells exposed to various concentrations of ANTX-a in vitro are shown in Figure 3. After $12 \mathrm{~h}$ of exposure, the percentages initially increased as the ANTX-a concentration increased. At $>1 \mathrm{mg} / \mathrm{L}$ ANTX-a, the percentages of apoptotic cells decreased; the percentages in the treatment group with a high ANTX-a concentration $(1 \mathrm{mg} / \mathrm{L})$ increased 1.08-fold compared with that of the untreated group $(p<0.01)$. These results suggested that ANTX-a causes the 


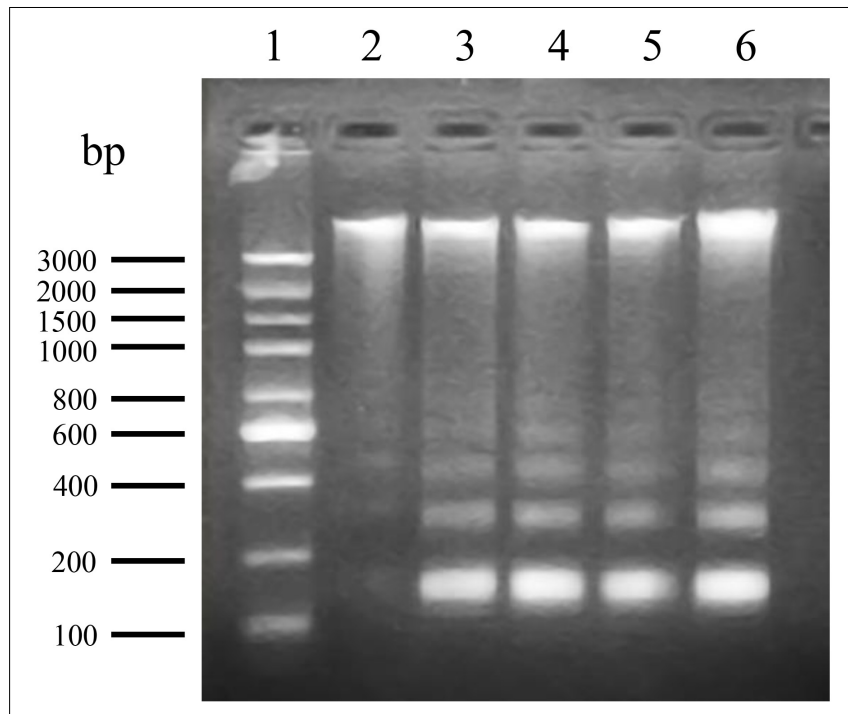

FIGURE 2 | DNA fragmentation of carp immunocytes treated with ANTX-a determined by agarose gel electrophoresis. Lane 1: 100-3000 bp molecular size markers of DNA ladder; lane 2: DNA from control lymphocytes; lanes 3-6: DNA ladder patterns of immunocytes induced by ANTX-a for $12 \mathrm{~h}$ at concentrations of $0.01,0.1,1$, and $10 \mathrm{mg} / \mathrm{L}$, respectively.



FIGURE 3 | Apoptotic effects of carp immunocytes were detected after treatment with $0.01,0.1,1$, and $10 \mathrm{mg} / \mathrm{L}$ ANTX-a for $12 \mathrm{~h}$. Data represent the mean $\pm S D$, and significant differences from the control were determined as ${ }^{*} p<0.05$ and ${ }^{* *} p<0.01$.

apoptosis of fish lymphocytes. Necrosis occurred when the exposure concentration was $10 \mathrm{mg} / \mathrm{L}$.

\section{Analysis of ROS and MDA Contents}

The ROS contents in fish lymphocytes treated with different concentrations of ANTX-a in vitro for $12 \mathrm{~h}$ were measured using flow cytometry. Figure 4 shows that the ROS levels increased with increasing ANTX-a concentration. The ROS content of the group exposed to the lowest concentration of ANTX-a $(0.01 \mathrm{mg} / \mathrm{L})$ significantly increased compared with that of the

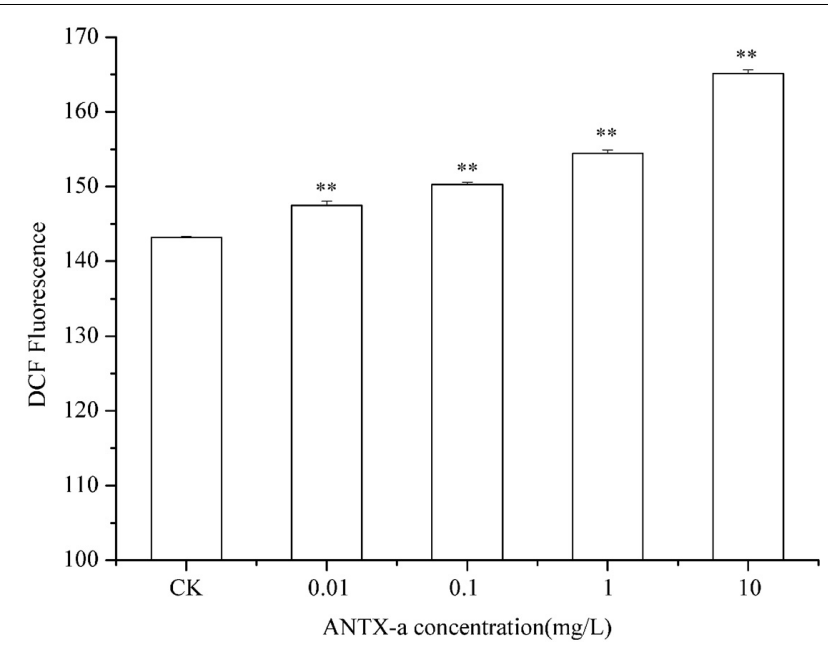

FIGURE 4 | Changes in intracellular ROS levels of carp immunocytes were determined after cells were treated with ANTX-a $(0.01,0.1,1$, and $10 \mathrm{mg} / \mathrm{L})$ for $12 \mathrm{~h}$. Data represent the mean $\pm \mathrm{SD}$, and a significant difference from the control was determined as ${ }^{\star \star} p<0.01$.

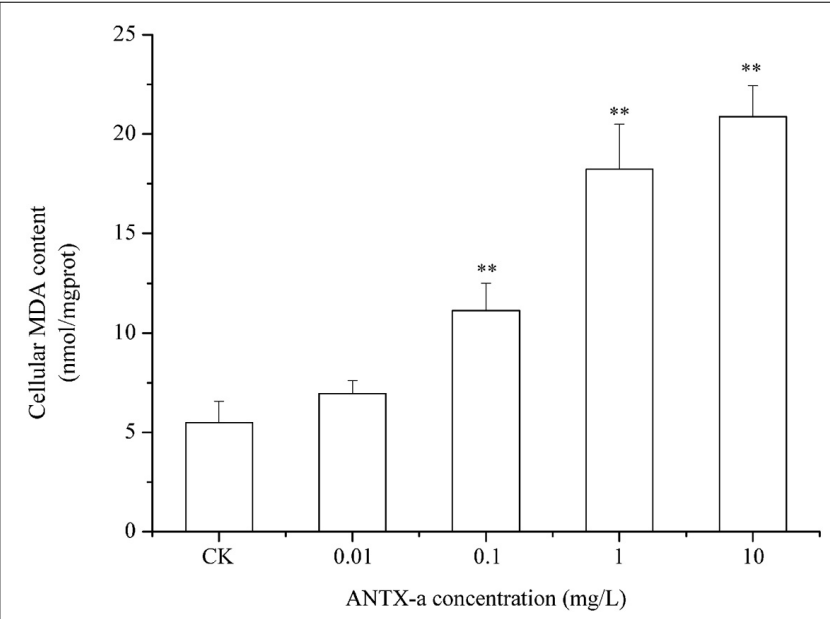

FIGURE 5 | Dose-dependent effects of ANTX-a on MDA content in carp immunocytes. Cells were treated with $0.01,0.1,1$, and $10 \mathrm{mg} / \mathrm{L}$ ANTX-a for $12 \mathrm{~h}$. Data represent the mean $\pm S D$, and a significant difference from the control was determined as ${ }^{* \star} p<0.01$.

control $(p<0.01)$. The generation of intracellular ROS induced by ANTX-a exhibited a dose-dependent increase. According to Figure 5, ANTX-a induced MDA formation in the lymphocytes. The MDA level of the $0.1 \mathrm{mg} / \mathrm{L}$ ANTX-a-treated group was more than twofold higher than that of the control $(p<0.01)$. Overall, the elevation of MDA induced by ANTX-a was also dose-dependent.

\section{Determination of SOD and CAT Activities}

SOD and CAT are critical antioxidant enzymes in cells. After the fish lymphocytes were exposed to different concentrations of ANTX-a for $12 \mathrm{~h}$, the activities of SOD and CAT were, respectively, detected (Figures 6, 7). Figure 6 shows that 


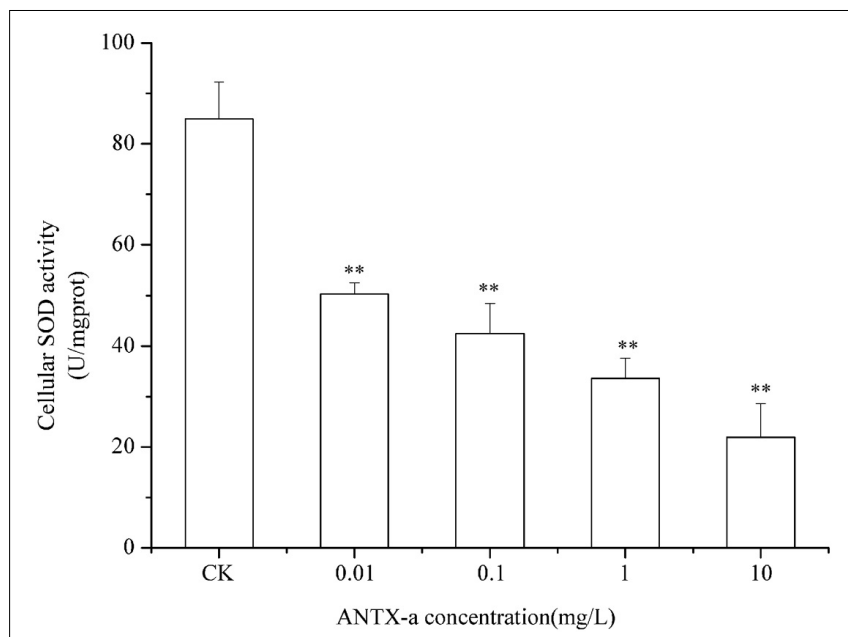

FIGURE 6 | SOD activity in carp immunocytes exposed to ANTX-a for $12 \mathrm{~h}$. ANTX-a concentrations were 0.01, 0.1, 1, and $10 \mathrm{mg} / \mathrm{L}$. Dose-dependent effects were also detected. Data represent the mean $\pm \mathrm{SD}$, and a significant difference from the control was determined as ${ }^{* *} p<0.01$.

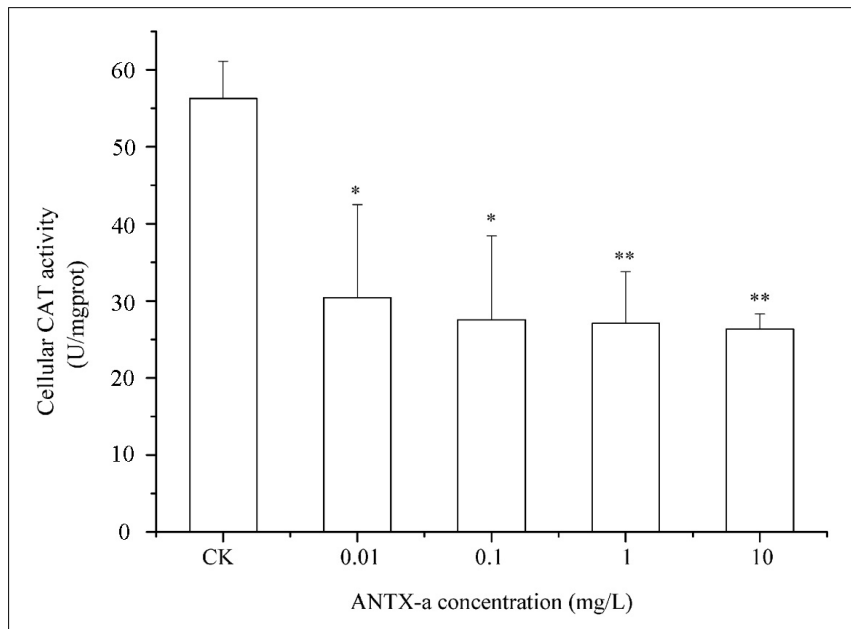

FIGURE 7 | Changes in CAT activity after carp immunocytes were treated with $0.01,0.1,1$, and $10 \mathrm{mg} / \mathrm{L}$ ANTX-a for $12 \mathrm{~h}$. CAT activity was determined using a CAT activity kit. Data represent the mean $\pm \mathrm{SD}$, and a significant difference from the control was determined as ${ }^{*} p<0.05$ and ${ }^{* *} p<0.01$.

SOD activity in fish lymphocytes significantly decreased with increasing ANTX-a exposure concentration. The activity of SOD of the $0.01 \mathrm{mg} / \mathrm{L}$ ANTX-a -treated group decreased by $41 \%$ compared with that of the untreated group. As shown in Figure 7, the CAT activity of lymphocytes in all of the ANTX-a-treated groups decreased. Compared with that of the untreated groups, the CAT activity decreased by $46 \%(p<0.05)$ in the group exposed to $0.01 \mathrm{mg} / \mathrm{L}$ ANTX-a.

\section{GSH Levels in Fish Lymphocytes}

In the dose-dependent experiment, the GSH levels in each group are shown in Figure $\mathbf{8}$, in which the GSH content distinctly

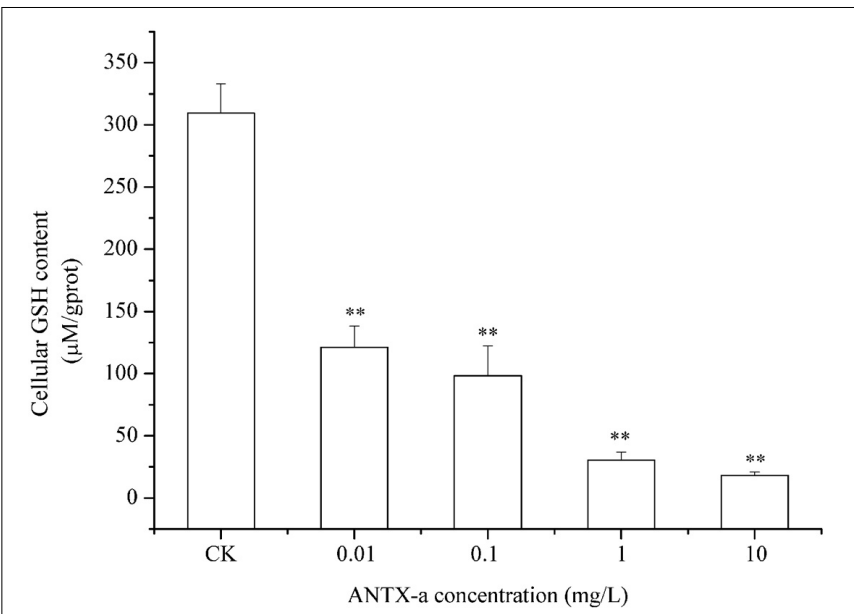

FIGURE 8 | ANTX-a effects on GSH levels in carp immunocytes after treatment with ANTX-a for $12 \mathrm{~h}$. GSH contents were detected to have dose-dependent effects. Data represent the mean $\pm \mathrm{SD}$, and a significant difference from the control was determined as ${ }^{* *} p<0.01$.

decreased in all ANTX-a-treated groups. The GSH content of the group treated with the lowest ANTX-a concentration $(0.01 \mathrm{mg} / \mathrm{L})$ decreased significantly by about $61 \%$ compared with that of the control group $(p<0.01)$. All of these results indicated that GSH levels in ANTX-a-treated lymphocytes were also dosedependent.

\section{Analysis of GR, GPx, and GST Activities in Fish Lymphocytes}

Figures 9-11 show the activities of GR, GPx, and GST in fish lymphocytes exposed in vitro to varying ANTX-a concentrations for $12 \mathrm{~h}$. The activities of GR and GPx in fish lymphocytes were sensitive to ANTX-a after $12 \mathrm{~h}$ of exposure regardless of treatment concentration. Figures 9, 10 show that the activities of GR and GPx significantly decreased as the ANTX-a concentration increased during $12 \mathrm{~h}$ of exposure; the activities of GR and GPx decreased by approximately 67 and $54 \%$ in the $0.01 \mathrm{mg} / \mathrm{L}$ treatment group compared with those of the control, respectively $(p<0.01)$. Figure 11 shows that GST activities decreased in all ANTX-atreated groups; the GST activity in cells treated with $10 \mathrm{mg} / \mathrm{L}$ ANTX-a significantly decreased compared with that in the untreated group $(p<0.01)$. Thus, the activities of GR, GPx, and GST were observed to be affected by ANTX-a in a dose-dependent manner.

\section{DISCUSSION}

As a neurotoxin, the potential threat of ANTX-a to the immune system of aquatic organisms has long been underestimated. Lymphocytes in fish, which are very sensitive to water pollution, play a vital role in enhancing adaptive immunity, regulating tissue inflammation and host protection (Vivier et al., 2018). Most effects of ANTX-a exposure on the morphological and 


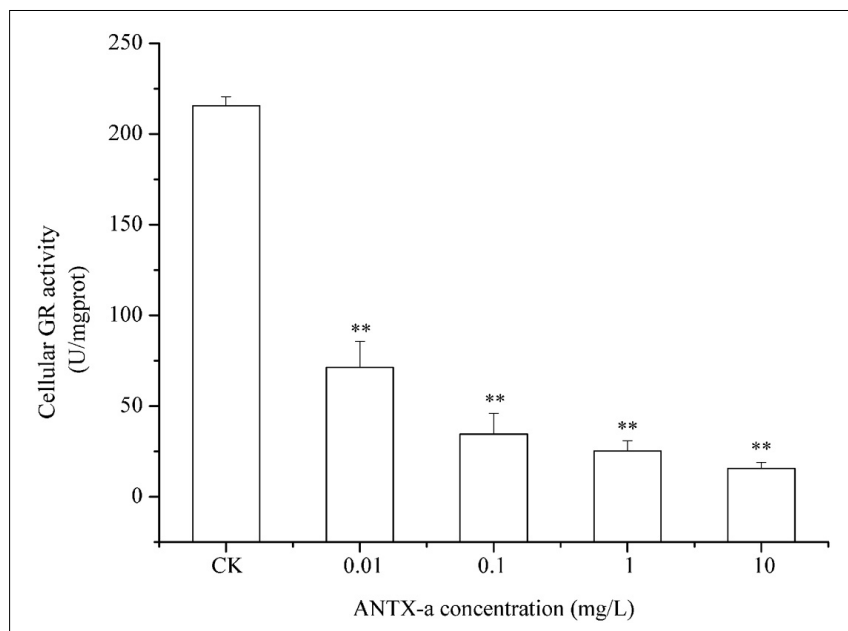

FIGURE 9 | GR activity in carp immunocytes after exposure to ANTX-a for $12 \mathrm{~h}$. The exposure concentrations of ANTX-a were 0.01, 0.1, 1, and $10 \mathrm{mg} / \mathrm{L}$. Data represent the mean $\pm \mathrm{SD}$, and a significant difference from the control was determined as ${ }^{\star *} p<0.01$.

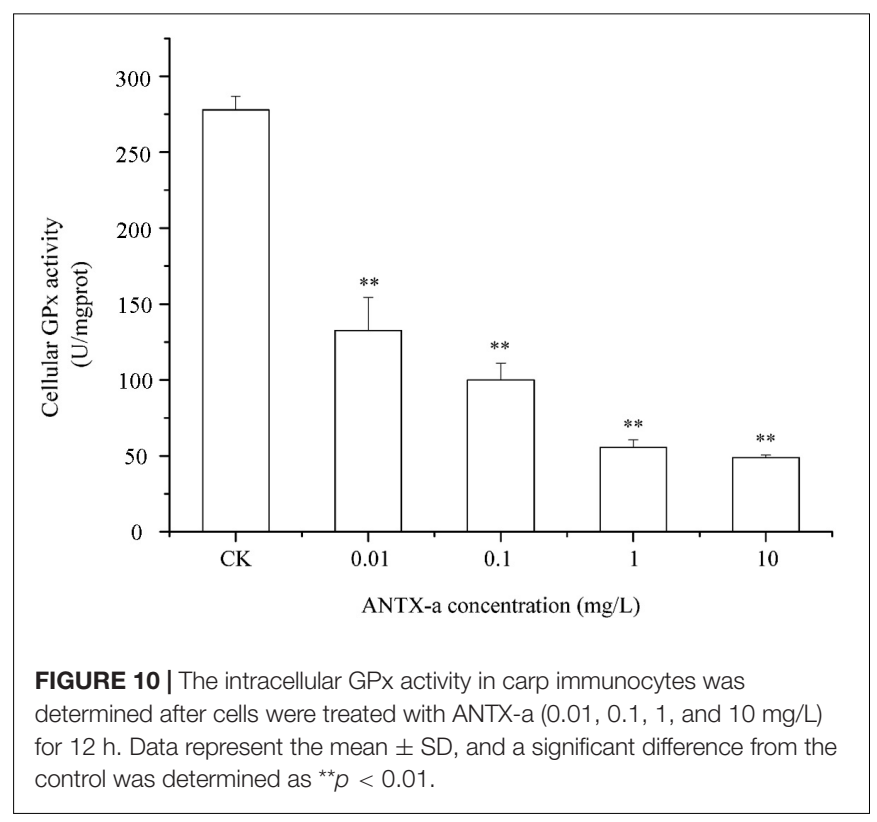

functional tissues of animals involve lymphocytes, such as low-dose ANTX-a-induced inflammation and apoptosis of immune cells and mouse brain cells (Takser et al., 2016). Although ANTX-a shows widespread occurrence and is highly toxic to animals, little is known about its mechanism of action and biotransformation in vertebrates, especially its toxic mechanisms underlying its impact on the fish immune system. Thus, we used the lymphocytes as our study object, and we detected the activities of major antioxidant enzymes to evaluate the toxic effects and related mechanisms of ANTX-a on fish.

In this study, the apoptosis of fish lymphocytes after ANTXa exposure was investigated. In addition, our results showed

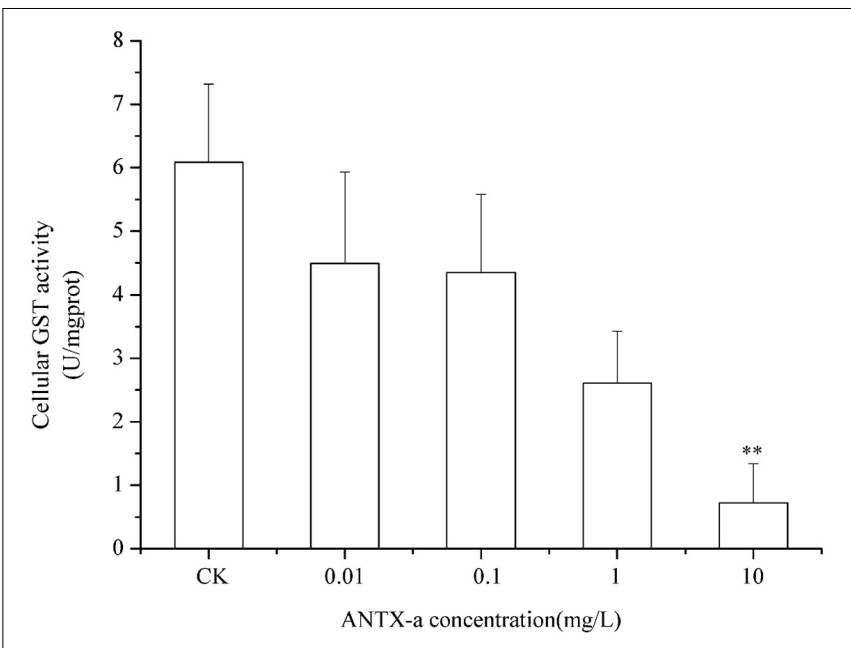

FIGURE 11 | GST activity in cells treated with ANTX-a for $12 \mathrm{~h}$. ANTX-a concentrations were $0.01,0.1,1$, and $10 \mathrm{mg} / \mathrm{L}$. Data represent the mean $\pm S D$, and a significant difference from the control was determined as ${ }^{* *} p<0.01$.

that ANTX-a exposure activated major antioxidant enzymes (e.g., CAT, SOD) and induced the accumulation of MDA and ROS by damaging the activities of SOD, CAT, GSH, GR, and GPx. To illustrate the types of lymphocytes apoptosis, the changes in intracellular DNA and organelles were analyzed. As shown in Figures 1, 2, marked DNA fragmentation, condensed cytoplasm, and swollen mitochondria were observed in the highest concentration group $(10 \mathrm{mg} / \mathrm{L})$, which was similar to our previous research (Zhang et al., 2012). DNA fragmentation is a great description of biochemical changes in apoptosis (Wyllie, 1980). Thus, the apoptosis of fish lymphocytes which induced by ANTX-a may have been attributed to mitochondrial damage and DNA fragmentation. ANTX-a at $10 \mathrm{mg} / \mathrm{L}$ was reported to reduce the ATP level of leukocytes in vitro, and a concentration-dependent reduction in the proliferative capacity of $\mathrm{T}$ and $\mathrm{B}$ lymphocytes has also been observed (Bownik et al., 2012).

In order to expound the mechanism of mitochondrial damage induced by ANTX-a, ROS, and MDA, indices of oxidative stress were determined in our study. ROS, including superoxide anion radicals, hydrogen peroxide, and hydroxyl radicals, which are created by aerobic organisms, particularly in the mitochondrial respiratory chain, play a major role in hypoxia adaptation and cell proliferation (Zhao et al., 2019). However, excessive ROS may lead to irreversible cell damage and even cell death, which is called oxidative stress. Lipid peroxidation (measured as MDA), which is used as a biomarker for the degree of oxidative stress and damage, affecting membrane mobility and the integrity of membrane-related biomolecule (Wei and Yang, 2015). Many studies report that chemical environmental pollutants can induce ROS production in fish cells (Garcia-Gomez et al., 2020). Gagnaire et al. (2019) revealed that DNA damage and ROS production were caused by the exposure of tritiated water. Our previous studies also showed 
the increase of ROS in cells after exposed to nodularin and microcystins (Zhang et al., 2014a). Likewise, exposure to ANTXa for $12 \mathrm{~h}$ in our study induced a dose-dependent increase in the level of ROS and MDA in fish lymphocytes compared with those of the untreated group (Figures 4, 5). MicrocystinLR can trigger intestinal DNA damage caused by excess ROS (Wen et al., 2019); saxitoxin can promote MDA production to induce lipid peroxidation (Melegari et al., 2012). It is apparent that high concentrations of ROS and MDA can be induced by cyanotoxins, and the generation of ROS is always accompanied by MDA products. These results indicated that ANTX-a leads to excessive ROS production resulting in oxidative stress.

However, occurrence of oxidative stress is closely related to the antioxidant system. CAT and SOD, which decompose hydrogen peroxide and superoxide anions, are important in the first defense line of organisms against excess free radicals (Yang et al., 2014). SOD activity correlates well with the immune competence of aquatic organisms because SOD is significant in minimizing the oxidative damage to host cells in immune defenses (Ali et al., 2020). Poniedzialek et al. (2015) suggested that the exposure of cylindrospermopsin (CYN) induces a dose-dependent increase in $\mathrm{H}_{2} \mathrm{O}_{2}$ concentration in $0.5 \mathrm{~h}$, and when the concentration of $\mathrm{H}_{2} \mathrm{O}_{2}$ was highest, the activities of SOD and CAT decreased significantly. Similarly, in our study, Figures 6, 7 show that the activities of SOD and CAT in fish lymphocytes were all reduced in the lowest ANTX-a exposure group $(0.01 \mathrm{mg} / \mathrm{L})$ compared with those in the untreated groups, and the changes in SOD activity were more obvious than those in CAT activity. Pinho et al. (2005) discovered that at the end of the experiment, CAT activity was found to be significantly reduced in crabs exposed to the highest dose of Microcystis aeruginosa extract. Excessive ROS can inhibit the activity of CAT, and the inhibition of CAT activity directly leads to an increase in $\mathrm{H}_{2} \mathrm{O}_{2}$, which results in the inhibition of SOD activity, thus forming a vicious cycle (Hernandez et al., 2013). In addition, the enzyme activities of the endogenous antioxidant defense system reduced in the kidney of mice treated with Microcystinleucine arginine (Jos et al., 2005). These results demonstrated that ATNX-a can reduce the activities of antioxidant enzymes, which is also the reason why oxidative stress occurred in fish lymphocytes.

Throughout the entire antioxidant protection process, GR can catalyze GSSG to form GSH, and GPX catalysis can help GSH to remove $\mathrm{H}_{2} \mathrm{O}_{2}$ from cells. GSH, an important nonenzyme antioxidant substance in cells, can prevent oxidative damage caused by reactive oxidants, can directly or indirectly maintain intracellular oxidative balance, and plays a significant role in protecting cells from oxidative stress (Ali et al., 2020). Rymuszka and Sieroslawska (2018) revealed that in primary leukocytes and small-cell lung cancer cells exposed to nodularin $(0.01-0.1 \mathrm{mu} \mathrm{g} / \mathrm{mL})$, intracellular ROS production increased significantly and GSH levels decreased. As is shown in our results, the GSH content and the activities of its corresponding enzymes GPx and GR were significantly reduced in the lymphocytes compared to those in the untreated group (Figures 8-10); the activities of GR and GPx decreased by approximately 67 and $54 \%$ in the $0.01 \mathrm{mg} / \mathrm{L}$ treatment group compared with those in the control, respectively $(p<0.01)$. The decrease in GPx activity may be due to the reduced GSH content, as previously demonstrated by Li et al. (2003). As an antioxidant enzyme that catalyzes the conversion of NADPH-dependent oxidized GSH (GSSG) to GSH, the loss of GR activity is a direct reason for the reduced GSH levels. Therefore, a reduction in the conversion of GSSG back to its reduced form (GSH) occurred following the low levels of GSH. Our previous study indicated that nodularin $(100 \mu \mathrm{g} / \mathrm{L})$ induced oxidative damage of fish lymphocytes via a reduced GSH content and GPx activity (Zhang et al., 2014b).

In the present study, antioxidant and relevant enzymes were all reduced; compared with the that of the control, the GR and GPx activities of the $0.01 \mathrm{mg} / \mathrm{L}$ treatment group were reduced by approximately 67 and 54\%, respectively (Figures 9 , 10); thus, the antioxidant system of fish lymphocytes was destroyed by ANTX-a. In addition to GR and GPx, GST, as an enzyme mediator that binds GSH to hazardous compounds, plays a crucial role in the process of cell detoxification. As an electrophilic target, GSH can attack GSH nucleophiles by binding active sites, thus achieving antioxidant and detoxification functions (Mihaljevic et al., 2020). Figure 11 shows that GST activity in all fish lymphocytes exposed to ANTX-a in vitro for $12 \mathrm{~h}$ decreased in a dose-dependent manner regardless of treatment concentration. The inactivation of GST corresponded to changes in the antioxidant system. Cylindrospermopsin-administered fish showed a decrease in GST activity after 7 days of exposure (da Silva et al., 2018). However, Freitas et al. (2015) discovered that MC-LR and CYN can significantly increase GST activities in lettuce roots. Therefore, symbiosis with plants may indicate that aquatic organisms are more vulnerable to exposure to algal toxins. For the final oxidative stress parameter evaluated in our experiment, the changes in ROS contents were significantly less than those in antioxidant enzyme activities and antioxidants in fish lymphocytes; thus, ANTX-a induced apoptosis of fish immune cells mainly through disruption of the antioxidant system, which led to the overproduction of ROS and thus oxidative stress.

\section{CONCLUSION}

This study demonstrated that neurotoxic ANTX-a exhibited immunotoxicity in carp lymphocytes by induction of apoptosis in an apparent dose-dependent manner. Intracellular ROS, MDA, and contents and reduced activity of antioxidant enzymes, such as SOD, GST, and CAT, are the main biomarkers of the cytotoxicity of ANTX-a to carp immunocytes in vitro, which were also measured to assess the influence of ANTX-a on fish lymphocytes and to investigate the potential mechanism of ANTX-a-induced immunotoxicity. These results suggested that ANTX-a induces the apoptosis of fish immune cells mainly by destroying the antioxidant system, causing excessive ROS production, and, finally, inducing oxidative stress. Further studies are needed to 
expound the exact mitochondrion apoptotic pathway involved in the apoptosis of ANTX-a induced in fish lymphocytes.

\section{DATA AVAILABILITY STATEMENT}

All datasets generated for this study are included in the article/supplementary material.

\section{ETHICS STATEMENT}

The animal study was reviewed and approved by the Experimental Animal Ethics Committee of Hangzhou Normal University.

\section{REFERENCES}

Ali, S. S., Ahsan, H., Zia, M. K., Siddiqui, T., and Khan, F. H. (2020). Understanding oxidants and antioxidants: classical team with new players. J. Food Biochem. 44:e13145. doi: 10.1111/jfbc.13145

Bortner, C. D., Oldenburg, N. B. E., and Cidlowski, J. A. (1995). The role of DNA fragmentation in apoptosis. Trends Cell Biol. 5, 21-26. doi: 10.1016/s09628924(00)88932-1

Bownik, A., Rymuszka, A., Sieroslawska, A., and Skowronski, T. (2012). Anatoxina induces apoptosis of leukocytes and decreases the proliferative ability of lymphocytes of common carp (Cyprinus carpio L.) in vitro. Pol. J. Vet. Sci. 15, 531-535. doi: 10.2478/v10181-012-0082-7

Bumke-Vogt, C., Mailahn, W., and Chorus, I. (1999). Anatoxin-a and neurotoxic Cyanobacteria in German lakes and reservoirs. Environ. Toxicol. 14, 117-125. doi: 10.1002/(SICI)1522-7278(199902)14:13.0.CO;2-V

Carneiro, M., Gutierrez-Praena, D., Osorio, H., Vasconcelos, V., Carvalho, A. P., and Campos, A. (2015). Proteomic analysis of anatoxin-a acute toxicity in zebrafish reveals gender specific responses and additional mechanisms of cell stress. Ecotoxicol. Environ. Saf. 120, 93-101. doi: 10.1016/j.ecoenv.2015.05.031

Chia, M. A., Kramer, B. J., Jankowiak, J. G., Bittencourt-Oliveira, M. D. C., and Gobler, C. J. (2019). The individual and combined effects of the cyanotoxins, anatoxin-a and microcystin-LR, on the growth, toxin production, and nitrogen fixation of prokaryotic and eukaryotic algae. Toxins 11:43. doi: 10.3390/ toxins 11010043

Cires, S., and Ballot, A. (2016). A review of the phylogeny, ecology and toxin production of bloom-forming Aphanizomenon spp. and related species within the Nostocales (cyanobacteria). Harmful Algae 54, 21-43. doi: 10.1016/j.hal. 2015.09.007

da Silva, R. D. C., Grotzner, S. R., Moura Costa, D. D., Esquivel Garcia, J. R., and Muelbert, J. (2018). Comparative bioaccumulation and effects of purified and cellular extract of cylindrospermopsin to freshwater fish Hoplias malabaricus. J. Toxicol. Environ. Health Part A Curr. Issues 81, 620-632. doi: 10.1080/ 15287394.2018.1469101

Du, X., Liu, H., Yuan, L., Wang, Y., Ma, Y., Wang, R., et al. (2019). The diversity of cyanobacterial toxins on structural characterization, distribution and identification: a systematic review. Toxins 11:530. doi: 10.3390/toxins11090530

Fernandez-Blanco, C., Font, G., and Ruiz, M.-J. (2015). Oxidative DNA damage and disturbance of antioxidant capacity by alternariol in Caco-2 cells. Toxicol. Lett. 235, 61-66. doi: 10.1016/j.toxlet.2015.03.013

Fitzgeorge, R. B., Clark, S. A., and Keevil, C. W. (1994). "Routes of intoxication," in Detection Methods for Cynobacterial Toxins, eds G. A. Codd, T. M. Jefferies, and C. W. Keevil (Cambridge: The Royal Society of Chemistry), 69-74.

Freitas, M., Azevedo, J., Pinto, E., Neves, J., Campos, A., and Vasconcelos, V. (2015). Effects of microcystin-LR, cylindrospermopsin and a microcystinLR/cylindrospermopsin mixture on growth, oxidative stress and mineral content in lettuce plants (Lactuca sativa L.). Ecotoxicol. Environ. Saf. 116, 59-67. doi: 10.1016/j.ecoenv.2015.02.002

\section{AUTHOR CONTRIBUTIONS}

YZ designed the study, writing, and interpretation of the results. LS, XY, DZ, YH, YL, YD, WZ, and JD carried out most of the experimental work. HZ had overall responsibility for the project and editing the whole manuscript.

\section{FUNDING}

This work was supported by the Key Research and Development project of Science Technology Department of Zhejiang Province (Grant No. 2017C02026).

Gagnaire, B., Arcanjo, C., Cavalie, I., Camilleri, V., Simon, O., Floriani, M., et al. (2019). Tritiated water exposure in zebrafish, Danio rerio: effects on the early-life stages. Environ. Toxicol. Chem. 39, 648-658. doi: 10.1002/etc.4650

Garcia-Gomez, C., Garcia, S., Obrador, A., Almendros, P., Gonzalez, D., and Dolores Fernandez, M. (2020). Effect of ageing of bare and coated nanoparticles of zinc oxide applied to soil on the $\mathrm{Zn}$ behaviour and toxicity to fish cells due to transfer from soil to water bodies. Sci. Total Environ. 706:135713. doi: 10.1016/j.scitotenv.2019.135713

Heldman, C. J., Krick, W. R., Perkins, D. A. K., Harrahy, E. A., and Sonzogni, W. C. (2008). New measurements of cyanobacterial toxins in natural waters using high performance liquid chromatography coupled to tandem mass spectrometry. J. Environ. Q. 37, 1817-1824. doi: 10.2134/jeq2007.0368

Hernandez, A. F., Lacasana, M., Gil, F., Rodriguez-Barranco, M., Pla, A., and Lopez-Guarnido, O. (2013). Evaluation of pesticide-induced oxidative stress from a gene-environment interaction perspective. Toxicology 307, 95-102. doi: 10.1016/j.tox.2012.09.007

Huguet, A., Lanceleur, R., Quenault, H., Le Hegarat, L., and Fessard, V. (2019). Identification of key pathways involved in the toxic response of the cyanobacterial toxin cylindrospermopsin in human hepatic HepaRG cells. Toxicol. Vitro. 58, 69-77. doi: 10.1016/j.tiv.2019. 03.023

Ibelings, B. W., and Havens, K. E. (2008). "Cyanobacterial toxins: a qualitative meta-analysis of concentrations, dosage and effects in freshwater, estuarine and marine biota," in Cyanobacterial Harmful Algal Blooms: State of the Science and Research Needs, ed. H. K. Hudnell (Berlin: Springer), 675-732. doi: 10.1007/ 978-0-387-75865-7_32

Jos, A., Pichardo, S., Prieto, A. I., Repetto, G., Vazquez, C. M., Moreno, I., et al. (2005). Toxic cyanobacterial cells containing microcystins induce oxidative stress in exposed tilapia fish (Oreochromis sp.) under laboratory conditions. Aquat. Toxicol. 72, 261-271. doi: 10.1016/j.aquatox.2005. 01.003

Li, X., Liu, Y., Song, L., and Liu, J. (2003). Responses of antioxidant systems in the hepatocytes of common carp (Cyprinus carpio L.) to the toxicity of microcystin-L R. Toxicon 42, 85-89. doi: 10.1016/s0041-0101(03)00104-1

Loftin, K. A., Graham, J. L., Hilborn, E. D., Lehmann, S. C., Meyer, M. T., Dietze, J. E., et al. (2016). Cyanotoxins in inland lakes of the United States: occurrence and potential recreational health risks in the EPA National Lakes Assessment 2007. Harmful Algae 56, 77-90. doi: 10.1016/j.hal.2016.04.001

Melegari, S. P., Perreault, F., Moukha, S., Popovic, R., Creppy, E. E., and Matias, W. G. (2012). Induction to oxidative stress by saxitoxin investigated through lipid peroxidation in Neuro $2 \mathrm{~A}$ cells and Chlamydomonas reinhardtii alga. Chemosphere 89, 38-43. doi: 10.1016/j.chemosphere.2012.04.009

Metcalf, J. S., Banack, S. A., Powell, J. T., Tymm, F. J. M., Murch, S. J., Brand, L. E., et al. (2018). Public health responses to toxic cyanobacterial blooms: perspectives from the 2016 Florida event. Water Policy 20, 919-932. doi: 10. 2166/wp.2018.012

Mihaljevic, I., Basica, B., Marakovic, N., Kovacevic, R., and Smital, T. (2020). Interaction of organotin compounds with three major glutathione 
S-transferases in zebrafish. Toxicol. Vitro 62:104713. doi: 10.1016/j.tiv.2019. 104713

Pinho, G. L. L., da Rosa, C. M., Maciel, F. E., Bianchini, A., Yunes, J. S., Proenca, L. A. O., et al. (2005). Antioxidant responses and oxidative stress after microcystin exposure in the hepatopancreas of an estuarine crab species. Ecotoxicol. Environ. Saf. 61, 353-360. doi: 10.1016/j.ecoenv.2004.11.014

Poniedzialek, B., Rzymski, P., and Karczewski, J. (2015). The role of the enzymatic antioxidant system in cylindrospermopsin-induced toxicity in human lymphocytes. Toxicol. Vitro 29, 926-932. doi: 10.1016/j.tiv.2015. 03.023

Rodriguez, I., Fraga, M., Alfonso, A., Guillebault, D., Medlin, L., Baudart, J., et al. (2017). Monitoring of freshwater toxins in European environmental waters by using novel multi-detection methods. Environ. Toxicol. Chem. 36, 645-654. doi: $10.1002 /$ etc. 3577

Ruibal-Conti, A. L., Ruiz, M. A., Rodriguez, M. I., Lerda, D., and Romero, M. D. (2019). Assessment of specific antibodies as biological indicators of human chronic exposure to microcystins. Ecotoxicol. Environ. Saf. 175, 236-242. doi: 10.1016/j.ecoenv.2019.03.071

Ruiz, M., Galanti, L., Ruibal, A. L., Rodriguez, M. I., Wunderlin, D. A., and Ame, M. V. (2013). First report of microcystins and anatoxin-a co-occurrence in san roque reservoir (Cordoba, Argentina). Water Air Soil Pollut. 224:17. doi: 10.1007/s11270-013-1593-2

Rymuszka, A., and Sieroslawska, A. (2009). The immunotoxic and nephrotoxic influence of cyanotoxins to vertebrates. Central Eur. J. Immunol. 34, 129-136.

Rymuszka, A., and Sieroslawska, A. (2018). Comparative studies on the cytotoxic effects induced by nodularin in primary carp leukocytes and the cells of the fish CLC line. Toxicon 148, 7-15. doi: 10.1016/j.toxicon.2018.04.001

Sieroslawska, A., and Rymuszka, A. (2019). Assessment of the cytotoxic impact of cyanotoxin beta-N-methylamino-L-alanine on a fish immune cell line. Aquat. Toxicol. 212, 214-221. doi: 10.1016/j.aquatox.2019.05.012

Smith, R. A., and Lewis, D. (1987). A rapid analysis of water for anatoxin a, the unstable toxic alkaloid from Anabaena flos-aquae, the stable non-toxic alkaloids left after bioreduction and a related amine which may be nature's precursor to anatoxin a. Vet. Hum. Toxicol. 29, 153-154. doi: 10.1016/S0955-2863(00) 00070-X

Svircev, Z., Lalic, D., Savic, G. B., Tokodi, N., Backovic, D. D., Chen, L., et al. (2019). Global geographical and historical overview of cyanotoxin distribution and cyanobacterial poisonings. Archiv. Toxicol. 93, 2429-2481. doi: 10.1007/ s00204-019-02524-4

Takser, L., Benachour, N., Husk, B., Cabana, H., and Gris, D. (2016). Cyanotoxins at low doses induce apoptosis and inflammatory effects in murine brain cells: Potential implications for neurodegenerative diseases. Toxicol. Rep. 3, 180-189. doi: 10.1016/j.toxrep.2015.12.008

Tavakkol-Afshari, J., Brook, A., and Mousavi, S. H. (2008). Study of cytotoxic and apoptogenic properties of saffron extract in human cancer cell lines. Food Chem. Toxicol. 46, 3443-3447. doi: 10.1016/j.fct.2008.08.018

Teneva, I., Mladenov, R., Popov, N., and Dzhambazov, B. (2005). Cytotoxicity and apoptotic effects of microcystin-LR and anatoxin-a in mouse lymphocytes. Folia Biol. 51, 62-67.
Trainer, V. L., and Hardy, F. J. (2015). Integrative monitoring of marine and freshwater harmful algae in washington state for public health protection. Toxins 7, 1206-1234. doi: 10.3390/toxins7041206

Vivier, E., Artis, D., Colonna, M., Diefenbach, A., Di Santo, J. P., Eberl, G., et al. (2018). Innate lymphoid cells: 10 years on. Cell 174, 1054-1066. doi: 10.1016/j. cell.2018.07.017

Wei, K., and Yang, J. (2015). Oxidative damage of hepatopancreas induced by pollution depresses humoral immunity response in the freshwater crayfish Procambarus clarkii. Fish Shellfish Immunol. 43, 510-519. doi: 10.1016/j.fsi. 2015.01.013

Wen, C., Zheng, S., Yang, Y., Li, X., Chen, J., Wang, X., et al. (2019). Effects of microcystins-LR on genotoxic responses in human intestinal epithelial cells (NCM460). J. Toxicol. Environ. Health Part A Curr. Issues 82, 1113-1119. doi: 10.1080/15287394.2019.1698498

Wyllie, A. H. (1980). Glucocorticoid-induced thymocyte apoptosis is associated with endogenous endonuclease activation. Nature 284, 555-556. doi: 10.1038/ $284555 \mathrm{a} 0$

Yang, Y., Ma, H., Zhou, J., Liu, J., and Liu, W. (2014). Joint toxicity of permethrin and cypermethrin at sublethal concentrations to the embryo-larval zebrafish. Chemosphere 96, 146-154. doi: 10.1016/j.chemosphere.2013.10.014

Zhang, H., Fang, W., Xiao, W., Lu, L., and Jia, X. (2014a). Protective role of oligomeric proanthocyanidin complex against hazardous nodularin-induced oxidative toxicity in Carassius auratus lymphocytes. J. Hazard. Mater. 274, 247-257. doi: 10.1016/j.jhazmat.2014.04.020

Zhang, H., Wu, Y., Fang, W., and Wang, D. (2014b). Regulatory effect of quercetin on hazardous microcystin-LR-induced apoptosis of Carassius auratus lymphocytes in vitro. Fish Shellfish Immunol. 37, 278-285. doi: 10.1016/j.fsi. 2014.02.015

Zhang, H., Shao, D., Wu, Y., Cai, C., Hu, C., Shou, X., et al. (2012). Apoptotic responses of Carassius auratus lymphocytes to nodularin exposure in vitro. Fish Shellfish Immunol. 33, 1229-1237. doi: 10.1016/j.fsi.2012.08.016

Zhang, H., Zhang, J., and Zhu, Y. (2008). In vitro investigations for the QSAR mechanism of lymphocytes apoptosis induced by substituted aromatic toxicants. Fish Shellfish Immunol. 25:717. doi: 10.1016/j.fsi.2008.02.008

Zhao, R.-Z., Jiang, S., Zhang, L., and Yu, Z.-B. (2019). Mitochondrial electron transport chain, ROS generation and uncoupling (Review). Intern. J. Mol. Med. 44, 3-15. doi: 10.3892/ijmm.2019.4188

Conflict of Interest: The authors declare that the research was conducted in the absence of any commercial or financial relationships that could be construed as a potential conflict of interest.

Copyright (c) 2020 Zhong, Shen, Ye, Zhou, He, Li, Ding, Zhu, Ding and Zhang. This is an open-access article distributed under the terms of the Creative Commons Attribution License (CC BY). The use, distribution or reproduction in other forums is permitted, provided the original author(s) and the copyright owner(s) are credited and that the original publication in this journal is cited, in accordance with accepted academic practice. No use, distribution or reproduction is permitted which does not comply with these terms. 